\title{
Conflict Pattern Analysis: Preparing the Ground for Participation in Policy Implementation
}

\author{
Alexandra Sauer \\ Published online: 21 October 2008 \\ (C) Springer Science+Business Media, LLC 2008
}

\begin{abstract}
The participation of non-state actors in implementation processes is often understood as a means to increase compliance efficiency. But the implementation of spatial policies frequently focuses on pre-established goals, processes and instruments and thus renders difficult open discourse and shared decision-making. This paper introduces conflict pattern analysis (CPA) as a tool that supports the analysis of the actual actor constellation in order to define efficient approaches that avoid common problems of participatory processes. CPA is a semi-formalised method that helps to identify key-actors, their relations and interaction amongst each other as well as their core beliefs, interests and resources. It aggregates this information to interaction patterns that can be compared, classified and linked to different participatory methods on a theoretically informed basis. Particularly on the local and regional level, this could be the first step for successful (participatory) implementation strategies.
\end{abstract}

Keywords Conflict analysis - Actor networks - Nature conservation · Implementation $\cdot$ Participation

\section{Introduction}

The transformation of European directives with environmental and spatial foci into visible action on local and regional level is even more fragmentary and belated than legal compliance in the European Union member states (CEC 2006). Implementation of land management policies, in particular, takes place in a highly politicised setting that is often characterised by conflicts between various actors competing for restricted resources such as space, money or influence (Niemelä et al. 2005; Stoll-Kleemann 2001; Valve 2002). Experience from spatial planning research suggests the potential of participatory techniques to deal with or prevent from such conflicts in order to reach and implement societal binding decisions that generate visible impact on land management. Correspondingly,

A. Sauer $(\bowtie)$

University Basel, Programme Sustainability Research, Klingelbergstr. 50, 4056 Basel, Switzerland

e-mail: alexandra.sauer@unibas.ch 
participation is requested by affected actors and civil society organisations for reasons of democracy and has become an administrative standard to assure legitimacy.

However, implementation takes place in a complex multilevel legal and administrative setting which channels the roles and options of the involved actors. The vertical interaction between different administrative levels and the horizontal interaction between different policy fields and organisations are strongly influenced by this institutional frame. European Directives leave little leeway for deliberation as they follow pre-established goals, processes and instruments. Hence, a kind of "administered participation" that utilises the niches left by the political programme is required in this context (Dahl 1994; Healey 1999) and makes high demands on the selection of appropriate participatory methods:

To start with, the current situation has to be analysed in order to frame the scope and conditions of the planned participatory process. Only on this basis it is possible to choose the appropriate method(s). This in turn requires a sound knowledge on the performance and prerequisites of available participatory techniques.

There is a growing body of literature, dealing with the purposes, prerequisites, scopes and potential impacts of available participation techniques in resource management. The contributions either reflect on meaningful evaluation criteria on a rather normative basis (Rowe and Frewer 2000) or strive for a systematic evaluation and comparison of empirical cases (Newig et al. 2006; van Asselt and Rijkens-Klomp 2002; Kallis et al. 2006; Stirling 2006; Rauschmayer and Wittmer 2006; Rowe and Frewer 2000 in research: Welp et al. 2006; Zierhofer and Burger 2007). Both strands of literature highlight the peculiarity of every specific case, but agree on three common categories of factors that influence the performance of participatory techniques. To sum up, these are the resources involved, the constellation of actors and the kind of outputs and/or outcomes at the end of the participatory process. These aspects are either described as variables that classify different techniques (e.g. techniques that are appropriate to involve several actors or techniques that strive for a final policy relevant document etc.) or as variables that could inform the choice of techniques (e.g. availability of resources, given conflict types within an actor constellation etc.). However, they give no indication on the assessment of the current situation that could support the definition of scope and prerequisites of a participatory process.

The methods for such assessments are still underdeveloped even though first attempts have been made. Development cooperation, for example, brought about approaches to obtain an understanding of the situation at hand which are still barely absorbed in Europe (Hjortsø et al. 2005).

Social network analysis has been applied to participation processes recently (Hubacek et al. 2006) but as it focuses on the quantity and frequency of relations it still falls short in analysing the available resources or the desirable outputs of a process; the quality and relevance of the relations and interactions between actors remain unclear (Hollstein 2006). Hence, no statement about the scope and conditions of a desirable participatory process can be made merely on the basis of a classic social network analysis. More pragmatic approaches of stakeholder analysis aim at a comprehensive understanding of actors (Breitschuh and Feige 2003), without connecting this knowledge explicitly to feasible participatory techniques.

To fill this gap, I propose Conflict Pattern Analysis (CPA) as a pragmatic analytical tool for the analysis of actor constellations prior to the participatory process. CPA has the potential to inform the choice of adequate (participatory) instruments by addressing:

- Actors including their rationales and action scopes and their resources.

- Conflict interactions in the affected policy field.

- Links to suitable steering and participation approaches. 
The paper is organised in the following way: to start with, I will shortly describe the empirical background that led to the development of CPA, followed by presenting the conceptual framework underlying this approach. In the main part, I describe CPA focusing on the operationalisation of central variables, the gathering of necessary data and their interpretation. This section is followed by conceptual considerations on how to link the results of CPA to established participation techniques. In the conclusion I will discuss the applicability of CPA in other contexts than policy implementation, highlighting the advantages and shortcomings compared to other, less formalised methods.

\section{Empirical Background: The Habitats Directive (92/43/EEC) in Germany}

The European Habitats Directive aims at establishing Natura 2000, a coherent network for the protection of habitats and species in the European Union. Its implementation faced difficulties in most member states and the intended time schedule was broken (CEC 2006). In Germany the selection of suitable sites that meet the directive's criteria was only completed in 2005, although scheduled for 1995. Next to legal inconsistencies, conflicts on local and regional level hampered implementation. The resistance of land users, land owners and their associations against the protection of private land amounted to demonstrations, lawsuits and political pressure and delayed the process. Furthermore, rivalry between administrative levels and departments and competition for tasks and budgets led to an inconsistent handling of Natura 2000. To analyse the reasons for these problems and to derivate management strategies for the protection of the sites, the German Federal Agency of Nature Conservation commissioned a scientific study on "enhancing the acceptance of Natura 2000-sites". This study was carried out under collaboration of the author at the chair of forest policy at the Technical University of Munich (Sauer et al. 2006). The initial data was gathered in ten qualitative case studies and consisted mainly of 64 problem oriented interviews with 74 people belonging to one of the following groups: nature conservation authorities, land-users and land-owners, conservationist associations, land-use associations, technical authorities (forestry, farming, fishery) and politicians. In this study, CPA was developed first for analytical purposes, then modified for practical use and applied in a praxis-oriented project of the German Landcare Association, a joint voluntary association of farmers, local communities and conservationists. The results of these studies will be used to illustrate CAP in section "Conflict Pattern Analysis" and to discuss the transferability of CPA to other subjects than implementation conflicts section ("Conclusion").

\section{Conceptual Framework}

In this paper, the development and implementation of natural resource management regimes is understood as a political process that aims at reaching societaly binding decisions on the use of restricted resources. The conceptual framework underlying CPA builds on this understanding of natural resource management as a political process and sees actors and their interaction as central elements in it.

In particular, collective actors like public administration or associations play an important role in natural resource management. Concepts of collective actors often expect them to act rationally and predictably in accordance with their stable organisational goals and norms. The division of work and their capacity to build up and manage huge 
knowledge stocks should provide them the necessary resources to strive effectively for their benefit (Geser 1990). However, due to the complexity and dynamics of the physical and social factors concerned in natural resource management, no complete knowledge on the system can be obtained. The prerequisites and impacts of organisational decisions and actions remain uncertain. This is why (collective) actors in this paper are conceptualised as seekers for their subjective expected utility: they strive for rational reasoning, but rely also on features like ideologies, stereotypes and habits that help to reduce complexity (Esser 1990; Geser 1990; Kronenberg 2005).

To conceptualise the interaction between actors in the realm of natural resource management as well as the impacts of these interactions on the physical world, I rely on policy analysis approaches. Policy analysis focuses on political processes with emphasis on the conditions and impacts of policy change. In this field, the Institutional Analysis Development Framework (IADF) of Elinor Ostrom and Edella Schlager, the Actor Centred Institutionalism (ACI) of Renate Mayntz and Fritz Scharpf and the Advocacy Coalitions Framework (ACF) of Paul Sabatier are elaborated concepts that guide research on actors, institutions and policy change (Ostrom 1999; Mayntz and Scharpf 1995; Sabatier and Jenkins-Smith 1999). They build on rational choice theory, but are open enough to allow for an intefgration of contributions of other disciplines like group psychology, organisational sociology or sociological action theories (Schlager 1999). Hence, they are suitable to catch the chosen concept of actors that strive for their subjective expected utility.

Even if they place different emphasis on the meaning of rules (Ostrom 2005), orientation and coordination (Mayntz and Scharpf 1995) or beliefs and preferences (Sabatier and Jenkins-Smith 1999), all three approaches have a similar understanding of the central elements of a political process. These are the actor arena, attributes of actors, the interaction of actors and the action context. To set up the conceptual framework of CPA that guides the analysis of natural resource management regimes, these elements have been adopted, specified and complemented (Fig. 1).

In the centre of the framework is the actor arena consisting of a certain amount of actors $(1-n)$ and their interactions. An actor is understood as an acting entity comprising one ore more persons (collective actors, organisations). Every actor has different resources he/she can use for action (e.g. material resources, knowledge, capabilities). As actions are deliberate attitudes of actors, the orientation of an actor directs her/his actions. The orientation in turn is composed of internal norms (values, culture, ideologies, stereotypes, habits...) and external norms (rules, expectations). Collective actors are composed of individuals that are characterised by their individual resources and orientation (cf. actor 2 in the figure). Following the considerations of Mayntz and Scharpf (1995), these individuals should only be considered individually if any action can solely be contributed to the individual and not the organisation as a whole (cf. also Geser 1990). The interaction of actors can be one-way or reciprocal and it is either persuasive or consenting. Inserted into a fourfold table, one can distinguish coordination, (consenting-reciprocal), consultation (consenting-one-way), information (persuasive-one-way) and conflict (persuasivereciprocal).

The interaction in the actor arena leads to or changes individual or collective action that has an effect on the physical world. However, in complex natural resource management regimes, such effects can only be ascribed partially to simple cause-and-effect relations. This is even more valid, as the action context has an impact on all features of the presented framework. It comprises stable and dynamic aspects of the physical world (e.g. habitats and species, weather, built environment...) and the social world (e.g. elections, existing institutions and institutional changes...). 

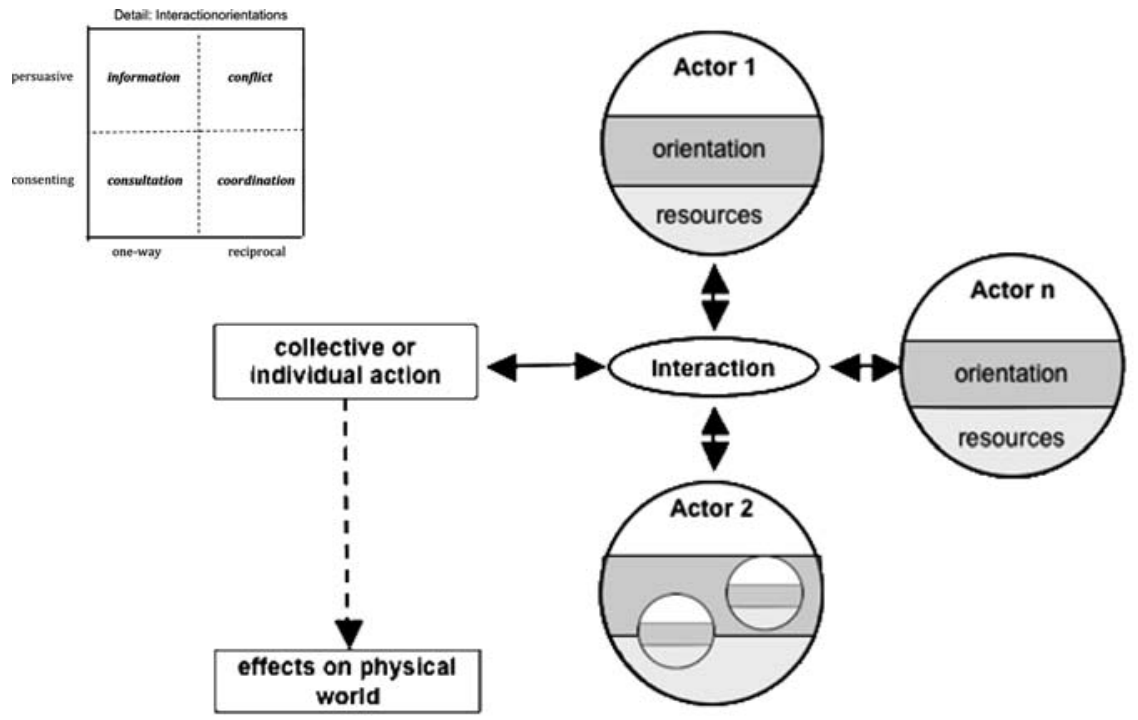

arena

action context

Fig. 1 Conceptual framework

Interventions into the political process in order to influence the development and implementation of natural resource management regimes can be operated from the outside by changing the action context or from the inside by changing one's behaviour and, hence, the interaction within the arena. Accordingly, participatory methods can be introduced from the outside (e.g. through administrative standards, legal innovations) or encouraged from inside the arena (e.g. self-organisation).

\section{Conflict Pattern Analysis}

In the following section I give a methodological introduction to CPA, starting with the operationalisation of the central variables deduced from the theoretical framework (Operationalisation of Central Variables), then describing how the primary data is aggregated to illustrative conflict patterns (Construction of Conflict Patterns) and outlining survey methods (Data Gathering). The interpretation of specific conflict patterns and their potential for a cross-case assessment are discussed afterwards (Analysis of Conflict Patterns).

Operationalisation of Central Variables

Actor Type

A common distinction of actors in stakeholder analysis and policy evaluation is made alongside their roles in the (policy) process, distinguishing between those potentially 
affected by a project or programme (primary stakeholders), those responsible for its design and execution (secondary stakeholders) and those acting as facilitators, hinderers or co-actors (external stakeholders). The latter exploit the process to pursue self-interests that are not necessarily connected to the policy field or issue under consideration (Busmann et al. 1997; Hjortsø et al. 2005; ODA 1995; Prittzwitz 1990). This concept of three actor types is challenged by the hybrid role of clientele oriented administration: whilst actors from civil society like non-governmental organisations and pressure groups are unquestionably external actors who strive to realise their own interests per definition, administrative actors can be seen as hybrids between external and primary stakeholders. Technical authorities like forestry administration, for example, are responsible for encouraging common welfare and the observance of European law but guard the interests of their clientele and their department at the same time (Krott 2001; Thomas 2003). To sum up, responsible actors, affected actors, external actors and hybrid actors are distinguished in CPA. This distinction allows for a first assessment of their general orientation and function that provides them role-dependent resources. Responsible actors, for example, are likely to take leadership in the formulation of procedures and standards, striving to be informed on the issue under consideration and are (at least partly) equipped with normsetting power.

To this functional classification an issue dimension must be added, which indicates the policy field an actor institutionally belongs to (e.g. forestry, nature conservation, energy). The specific characteristics of a policy field are part of the action context that shapes the orientation and interaction of actors in natural resource management conflicts. They are especially relevant as natural resource management usually affects different policy fields at the same time.

These two aspects of horizontal actor differentiation are complemented by a vertical component that incorporates the multilevel aspects of land management issues mentioned in the introduction. Every organisational level has different structures and shapes the action scope of the corresponding actors differently.

To sum up, the actor classification in CPA comprises functional, subject and multi-level aspects and allows the classification of every actor according to its role, its position and its main interest sphere.

\section{Resources}

The resources of an actor can be distinguished into those she potentially possesses and those she is willing to capitalise in a specific situation. For conflict analysis, the power potential of an actor, her potential to exert influence in an interaction situation is essential. This potential is highly dependent on the actor type as power resources are only effective if they are legitimised and accepted by other actors (Stark 2000). This recognition of resources is strongly connected to the role of an actor: a scientist, for example, will rather be respected as knowledge provider on ecological systems or the needs of a specific species than a farmer, no matter how profound the farmer's knowledge might be (Soini and Aakkula 2007). Hence, the power potential is a product of available resources and their successful usage.

Depending on the role and the main resources an actor possesses (e.g. working force, money, knowledge, capabilities, social capital and/or institutional support) four types of power potential are distinguished: (1) Definition power to shape a technical discourse. It depends on knowledge and on the credibility of this knowledge as explained above. (2) Informal power to organise approval or rejection among other actors. It depends on the 
networking capabilities as well as the number and type of supportive actors or members (typical for associations). (3) Material power to directly influence actors and processes. It depends on material resources like budget, money, real estate and employees. (4) Normative power to define rules and norms that are respected by others. It depends on the legal and administrative legitimisation of an actor.

The power potential of an actor can be estimated by assessing her formal and informal (executed) role and her available resources (e.g. members of an association, political contacts, institutional framework, budget).

\section{Orientation}

Understanding the orientation of actors in terms of their worldview, ideologies and their perception of a specific situation is necessary to estimate their commitment in natural resource management. Eliciting these orientations is an integral part of (participatory) processes and cannot be covered comprehensively prior to the management process. Nevertheless, it is important to assess the main orientations concerning the issue under consideration and concerning other actors to get a sound picture of the situation. Hanke et al. (2002) for example, highlight the importance of different framings of different stakeholder groups for the evolution (and with it also for the understanding) of environmental conflicts.

In CPA, the orientation towards issues and actors is differentiated by an activity dimension and an judgemental dimension following Beck's analysis of group processes (Beck 2001). Orientations are either activating, that is favouring action, or stabilizing and hence favouring passivity. Furthermore it can be rather positive or negative. Combining these dimensions, CPA distinguishes four orientations: approach (positive-activating), agreement (positive-stabilizing), rejection (negative-activating) and avoidance (negativestabilizing) (Fig. 2). They help to estimate the probability that one actor invests her proper resources in order to support or hamper a resource management process. Orientations can be estimated by analysing figurative expressions an actor uses. To give an example: talking about Natura 2000 as a "shroud for farmers" indicates disapproval and resignation and suggests only moderate activity against Natura 2000 which is taken for a (negative) fact (avoidance).

Fig. 2 Dimensions of actors' orientations

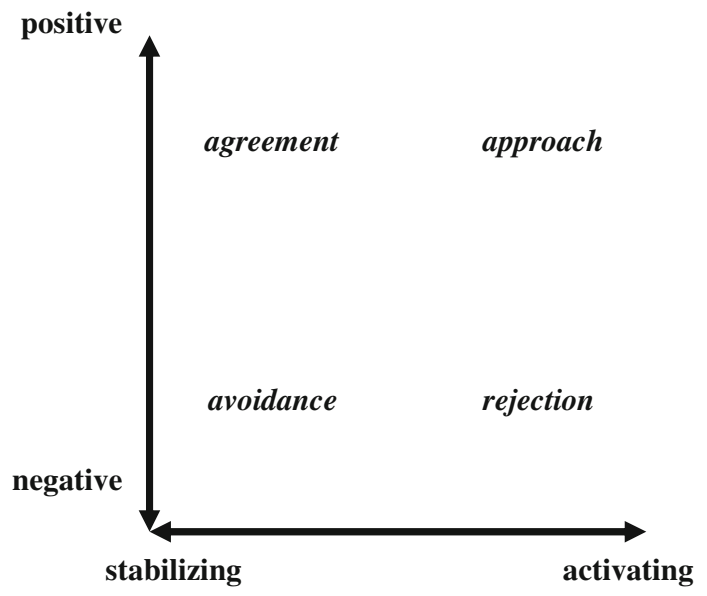


Whilst orientations are strongly influenced by internal norms, interests are more strongly shaped by external norms. They are linked to the resources an actor is striving for. Accordingly, in CPA, they are distinguished into four spheres: (1) to gain influence is the typical orientation of politicians, civil society actors and partly technical authorities (Thomas 2003) and entrepreneurs, (2) maintaining and gaining (financial) autonomy is the typical interest of affected actors that try to avoid constraints from new policies, (3) a broad societal legitimacy is one of the main interests of political actors and administration. (4) The development of normative standards like the "definition" of common welfare or "best practises" in natural resource management is typical for public administration.

Despite the close link between roles, resources and interests, actors often show a complex pattern of orientations and interests that can mutate depending on the specific action context. However, rejection and contradictory interests within an actor arena favour the emergence of conflicts.

\section{Conflict Types}

With reference to the conceptual framework, conflicts are understood as persuasive and reciprocal interaction between actors. They emerge if actors within an actor arena compete for resources, or if they have to fight for the recognition of their resources. Hence, conflicts are directly linked to the interests of actors. Dependent on the interests at stake, conflicts are relational, concerning the hierarchy and position within the actor arena (conflict of position), idealistic, concerning contradicting orientations (value conflict), material, concerning the distribution of material resources (distributional conflicts) or regulatory, concerning the validity and compliance of norms (rule conflict) (Giesen 1993). The higher the rationality of a conflict the less probable is an escalation that would lead to abandon formal or informal rules of a fair and societal accepted interaction. The closer the conflict issue is related to the internal orientation of an actor, in turn, the more emotional becomes the interaction. Conflicts of position directly affect the (social) position of an actor and have a high potential to be dealt with emotionally, value conflicts concern internalised orientations and with it partly the identity of actors, whereas distributional conflicts concern mainly the material belongings of actors. Rule conflicts are the most rational ones, as they are rather detached from individual convictions and rotate around the general meaning of norms and laws.

However, conflicts cannot be reduced to simple relations between two actors who compete for one particular resource (reciprocal conflict). They are often imbalanced in the sense that the interests at stake differ from actor to actor and lead to an "integrated or mixed conflict". A farmer, for example, might be highly emotionally engaged in arguing on the "right" farming practise (value conflict), whilst his opponent is only interested in forcing him to obey a decree on mowing dates for meadows (rule conflict). Latent or suppressed conflicts, in turn, can be unidirectional if they are only perceived by one actor whilst his "opponent" does not feel involved. This happens mainly in the interaction between individual and collective actors (e.g. client-administration). In CPA, accordingly, the direction of a conflict plays an important role: conflict types can only be specified by taking the perspective of specific actors. The orientation of one actor regarding other actors or issues indicates the potential of her, being involved in a conflict (rejection and avoidance). The interests at stake, determine the conflict type: striving for influence tends to result in conflicts of position, striving for being a standard setter induces value conflicts, striving for autonomy induces distributional conflicts and striving for legitimacy tends to result in rule conflicts. The resources of the actors in the action arena, in turn, determine the 
Table 1 Characteristics of different conflict types in terms of degree of rationalisation, prevalent interest sphere affected and the potential of different power resources for gaining influence in the conflict

\begin{tabular}{llllll}
\hline Conflict type & Interest sphere & \multicolumn{4}{l}{ Potential of resource type $^{\mathrm{a}}$} \\
\cline { 3 - 6 } & & Material & Definition & Informal & Norm setting \\
\hline Rationalisation & & & & & \\
Conflict of position & Influence (autonomy) & + & + & ++ & + \\
Value conflict & Standard setting (legitimacy) & o & ++ & ++ & + \\
Distributional conflict & Autonomy (influence) & ++ & + & + & + \\
Rule conflict & Legitimacy (standard setting) & o & o & + & ++ \\
\hline
\end{tabular}

${ }^{a}++$ great potential, + high potential, o medium potential to gain influence

potential for an escalation of conflicts as well as their potential to enforce their claims and to "win" a conflict.

As it was stated above, actors are often pursuing a complex pattern of interests, whereas the interest in developing normative standards is slightly linked with legitimacy and striving for influence is often connected to autonomy issues. Hence, rule conflicts tend to escalate to value conflicts, while distributional conflicts easily develop a positional component as well. Table 1 summarises the relations between conflict types, interest spheres and the usefulness of resources.

\section{Construction of Conflict Patterns}

With the specification of actor types, orientations and resources and their aggregation to conflict types, it is possible to draw a "picture" of the situation in the actor arena. For this purpose, every actor is assigned to her position in a two dimensional grid that reflects the institutional level and the policy field (issue dimension) an actor belongs to. Distinguishing further between primary, secondary, external and hybrid actors, every actor is classified with regard to the three main dimensions described in "Actor type". Then, the interactions between those actors are added, distinguishing between conflict types and the direction of these conflicts (reciprocal, one-way, mixed).

Such a diagram reveals a concise picture of the situation as it shows at a glance the prevalent conflict types (and with it the degree of rationalisation) and central and unaffected actors. As these insights are connected with the background information on policy fields, orientation and resources, it is possible to estimate the potential of escalation or settlement of the detected conflicts. Preliminary hypothesis on conflict drivers and the action scopes of the involved actors can be formulated. Figure 3 shows one example that is drawn from the underlying case study (case no. 9); the analysis of conflict patterns is further described in section "Analysis of Conflict Patterns".

\section{Data Gathering}

The gathering of necessary data depends on the purpose of CPA in the respective case. Applying it for scientific analysis, the whole array of (structured) methods of qualitative social research, ranging from document analysis, problem-oriented interviews to observation could and should be applied. Using CPA as a pragmatic analytical tool for designing 




Fig. 3 Graphical representation of conflict patterns

participatory processes, the data gathering has to be as simple as possible, mainly relying on general and accessible documents, protocols and every-day knowledge of administrative staff or other actors who are familiar with the case.

For the implementation of the Habitats Directive, a standardised checklist has been developed that starts with a general description of the case (main land-use activities, threats to habitats and species, experience with protection schemes). It also includes an overview over known actors and their orientation towards the issue under consideration (e.g. local Natura 2000 protection schemes). These insights were supplemented by an estimation of historic or latent conflicts and development in other policy fields that could effect the actual situation (e.g. unemployment, bad/good experience with nature conservation, the European Union, existing strategies in town and country planning...). These data could mainly be taken from standard data forms and local authorities that compiled the list. Such a checklist has to be tailor made for the specific question under consideration; hence, the instrument is more valuable, the more cases exist. If the available knowledge is not sufficient to get a clear understanding of the conflicts in the actor arena, short problem oriented interviews with key-actors proved to be helpful. Interviews have the advantage of forcing actors to explain their statements (often using figurative expressions that reveal their orientations) but are time and cost consuming and ask for a neutral third party conducting the interviews.

However, the conceptual structure of CPA allows for an integration of different types of empirical data that are complemented with theory driven considerations. Gaps can be filled (at least partially) by general considerations on the links between actor types, resources and conflicts within an actor arena. This reduces the need for empirical work to a minimum. 
Analysis of Conflict Patterns

A single conflict pattern shows the relations of actors in an actor arena and identifies affected and less affected actors; it indicates the core interests that are involved in the conflicts and reveals information about actor types, resources, orientation, affiliation and roles of actors. Thus, the heterogeneity or homogeneity of the actor arena, the vertical, horizontal or "diagonal" orientation of conflicts across institutional levels and policy fields and their degree of rationalisation become apparent. This reduces the risk of ignoring or misinterpreting conflicts and helps to discover their hidden drivers. Intra- and interagency conflicts, for example, are often underestimated in resource management. The (public) perception is mainly restricted to bipolar conflicts between "land-use" and "nature conservation" as they find their articulation via media, law suits etc. Conflicts, in this context, are often seen as distributional conflicts regarding the generation of proceeds through land use. This stereotyping of land management conflicts often covers underlying positional or value conflicts.

Ten cases that were analysed in the underlying case study (cf. section "Conceptual Framework") are shown in the annex. Case 2, for example, reveals the difficult relation between nature conservation and forestry administration. If situated at the same level, their conflicts are mainly rational (rule or distributional conflicts). Once there are more institutional levels involved, the relations become emotional as the agencies compete for influence and the conflicts get relational. The entire case is dominated by conflicts between forestry and nature conservation administration, with only one affected great landowner who is directly engaging on state level. He is involved in a "typical" distributional conflict as his main power resource is of material nature (real estate, jobs). In addition, he obviously possesses informal power through his lobbying and networking activities that allow him to intervene directly on federal state level. One community is playing an inferior part as it is not directly affected by conflicts but has a general interest in the issue due to its community development projects that might be affected by Natura 2000. Despite this low involvement in conflicts, an engagement as supportive third-party institution seems questionable as the community neither possesses normative, nor definition, nor material power in the corresponding policy field that would allow for an effective intervention.

Different is the situation in cases 6,8 and 10 with prevalent conflicts between the various levels of nature conservation administration that hamper the efficient implementation of Natura 2000. They originate mainly in the struggle for competences (=influence, autonomy) and differing normative standards between the administrative levels. Neither the "right" conservation approach nor the responsibilities for it are agreed upon. Apparently, such conflicts require rather internal organisation development strategies, than broad citizen participation, as it might be appropriate for the "typical" nature conservation conflict in case 2 .

As for the purpose of this paper, it would lead too far to describe the outcomes of all ten cases, but the potential of CPA for cross-case assessment becomes apparent. Unfolding prevalent constellations supports the search for adapted strategies on super ordinate levels instead of designing isolated solutions for single projects or cases. Policy making in natural resource management could benefit from the insights, gained from a bigger number of cases.

Apparently, the interpretation and comparison of different conflict patterns cannot be done without considering the action context. Individual case characteristics (like the occurrence of certain species, or the party a major belongs to) and more general factors that 
might influence a number of cases should be taken into consideration. In the realm of Natura 2000, for example, stable context factors have been the characteristics of occurring habitats and species (physical world), the prevalence of cooperative strategies in nature conservation, the system of the European Union, the performance orientation of public administration and the necessary budget consolidation (social world). Dynamic context factors have been flood events (physical world), upcoming elections, or the reorganisation of the public administration (social world).

Similar factors have been noted in other cases that are related to land management. Sneddon et al. (2002, p. 671), for example, highlight the role of normative, politicaleconomic and technological arenas in shaping interaction and discourses in water related conflicts

Despite their importance, such context factors are not included in the graphical representation of CPA. Due to its complexity, the social and physical context can only be modelled partially. It is indirectly represented, as it shapes the orientations and resources of the actors within the actor arena. Nevertheless, a closer assessment of the context supports the development of resource management strategies that address the identified conflict patterns. Such an assessment is part of the development of resource management strategies including the choice of adequate participatory methods.

\section{From Analysis to Process Design}

As it was stated in the introduction, participatory methods are mainly distinguished alongside their purpose and outcomes, their constellation of actors (actor attributes and interaction) and the necessary resources. These variables should inform the choice of adequate methods as they allow characterising different approaches according to their scopes and conditions. Figure 4 gives an aggregated overview over main distinction variables that are considered in recent literature on participation in natural resource management and planning (Newig et al. 2006; van Asselt and Rijkens-Klomp 2002; Kallis et al. 2006; Stirling 2006; Rauschmayer and Wittmer 2006; Rowe and Frewer 2000) and links them to the features of CPA. This connection allows building the bridge from the analysis of a current situation to the design of a participatory process.

The choice of participatory methods starts from a definition of the purpose of the planned process. CPA supports this step by discovering existent conflicts and their drivers. The conflict type(s) inform about the concerned interests and the degree of rationality within the actor arena. With this knowledge it is possible to decide whether participation should be consensual with an emphasis on the settlement of value or positional conflicts or if it is rather useful as a supportive tool to find best possible solutions for distributive or rule conflicts. Accordingly, techniques can be chosen that rather aim at reaching consensus or that aim at the rationalisation of a decision by eliciting and sharing different forms of knowledge.

However, the purpose of a participatory process is not only given through the specific situation within the actor arena but is also subject to context factors that can barely be influenced. Especially the goal to gain acceptance for predefined outcomes is often set by the social context. Laws have to be implemented and actors are forced to cultivate political majorities, just to mention two common pressures from the context. Even if they are not explicit, such frame conditions have to be taken into consideration when using CPA to decide on the goal of participatory processes. 


\begin{tabular}{|c|c|}
\hline & PURPOSE \\
\hline & Elicit information, increase knowledge $e^{\text {i.i.i,iikv }}$ \\
\hline & Mutual learming and reaching consensus, ii, iii, iv \\
\hline CONFLICT TYPE & Gaining acceptance for predefined outcome ${ }^{\text {w.jii }}$ \\
\hline Interests concerned & (required) bindingness of outcome $e^{i, i i, y, y i}$ \\
\hline Degree of rationalisation & INTERACTION \\
\hline Direction (one-way, mixed,...) & „all" interests covered by participants ${ }^{\text {viv }}$ \\
\hline Orientation (vertical, horizontal...) & Empowerment \& competencies ${ }^{\mathrm{i}, \mathrm{iii} i \mathrm{ij}}$ \\
\hline & Rule transparency $y^{\mathrm{iz} x_{2},{ }_{i}}$ \\
\hline ACTOR TYPE & Interration of different types of information ${ }^{\text {inii,vi }}$ \\
\hline $\begin{array}{l}\text { Composition of arena (level, } \\
\text { actor type) }\end{array}$ & Direction of interaction ${ }^{\mathrm{i}, \mathrm{ii}}$ \\
\hline ayailable resources in the arena & Decision mode ${ }^{\mathrm{i} i \mathrm{i}, 4}$ \\
\hline Orientation and interests & \\
\hline CONTEXT & Heterogeneous/homogeneous constellation ${ }^{\mathrm{i}, \mathrm{ii}}$ \\
\hline Physical world (static, dynamic) & Participants' openness ${ }^{i}$ \\
\hline Social world (static, dynamic) & Sensivity of issue for actor \\
\hline & Resource accessibility for participants" \\
\hline & $\cos T s$ \\
\hline & Absolute costs (money, facilitator) ${ }^{\mathrm{i}}$ \\
\hline $\begin{array}{l}\text { ii (Asselt and Rijkens-Klomp, 200 } \\
\text { iii (Kallis et al., 2006) }\end{array}$ & Efficiency (in relation to issue) ${ }^{\mathrm{r}, \mathrm{m}}$ \\
\hline $\begin{array}{l}\text { "(Stirling, 2006) } \\
\text { "(Rauschmayer and wittmer, } 2000 \\
\text { vi (Rowe and Frewer, 2000) }\end{array}$ & Cost for implementation of resultsi" \\
\hline
\end{tabular}

Fig. 4 Links between the characteristics of different participation techniques and the findings of CPA

Further, the prevalent conflict types can inform the choice of the interaction mode that is required. Depending on the direction of conflicts (one-way, mixed or reciprocal) it is more or less important to support reciprocal interaction or to empower the actors to 
advocate for their interests. Rule transparency and the integration of different types of information, for example, is necessary in mixed conflicts that affect different hierarchical levels and actor types. Relational conflicts between different authorities would benefit from an institutionalisation of interactions that clarifies their positions by transparent decision modes and competences. In contrast, distributional and value conflicts with individual landowners involved, could better benefit from the opportunity for mutual learning by integrating different types of information and a broad coverage of interests.

CPA builds on a sound analysis of the actor arena and helps to identify and characterise different actor types. This knowledge helps to choose participatory techniques that distinguish between their suitability for different attributes of the involved actors. Some techniques are useful to deal with homogeneous or heterogeneous constellations; others require a minimal openness within the actor arena. In contrast to the high emphasis on different interaction modes, research to participatory methods lays astonishingly little attention on the distinction of actor types and their resources. "Power differentials" are usually mentioned in terms of decision modes and the validity of knowledge ("local knowledge") but omit other resources of power and influence. CPA in this realm could be even more effective if there was more knowledge about the suitability of different participatory techniques with respect to the actor attributes.

Eventually, the price has to be taken into consideration when deciding on the "best" participatory method. Sometimes, the ideal process would be far too time and cost consuming in relation to the (un)importance of the issue under consideration. The settlement of highly emotional conflicts, for example, might be too cost intensive compared to the expectable benefit for the resource management issue. Sometimes it might be better to ignore escalated conflicts that concern only marginal areas and to concentrate the effort on other sites. These assessments are influenced by the social context, as they are dependent on the political support, budget issues and the public opinion.

In addition to the main conceptual connections between CPA and the choice of participatory methods described in this section, there are further more specific links that cannot be worked out into detail in this paper, as they are highly dependent on the specific case. The available resources within the actor arena, for example, could influence the methodological choice; it might be the case, that actors are prone to finance a facilitator and hence, support a method that would not be feasible otherwise.

\section{Conclusion}

CPA was developed and tested with the implementation of Natura 2000 on local and regional level in Germany. To estimate the transferability of CPA to other resource management scenarios, the characteristics of Natura 2000 and their implications for CPA are discussed in the following.

Implementation in the European Union takes place in a multilevel setting that involves a variety of collective actors and the subsidiary principle favours conflicts of position between different administrative levels. In spatially limited local cases, the multilevel approach of CPA might be useless, while a deeper look on emotionally driven personal conflicts might be necessary. Nevertheless, many policy fields have a multilevel component and a transfer of CPA to other resource management strategies - at least in federal systems of OECD countries-seems to be promising. 
Unlike other natural resource management issues, nature conservation goals usually have no private advocacy but are persecuted by public authorities or associations. A formalised tool like CPA is functional in this context as it benefits from the integration into standard administrative procedures. Dealing with issues that lack central responsible actors, it might be difficult to operate CPA when it comes to a practical application. CPA requires someone who carries out the analysis and who has norm setting power to integrate the results into decision making procedures. Experience of the German Landcare Association shows, that CPA is helpful to get insight into a field of actors. However, it only develops its full potential if the results are connected to ongoing administrative procedures.

Another particularity of nature conservation issues is their (re)distributive component that restricts the action scope of some actors while enlarging that of others. Typical common good issues like air pollution or freshwater management might affect different actor types and generate conflicts that are only partly covered by CPA. Even if the actor constellations in the sub-fields of natural resource management (water management, agriculture, nature conservation, forestry) are partly overlapping, some actors might take roles that provide them other resources than those considered in CPA. Nevertheless, the moderate formalisation of CPA allows for a comparison of different constellations. Particularly in research it could help to elicit "typical" natural resource management conflicts and inform promising strategies to prevent from these in the future.

Natura 2000 provides a large amount of cases that favour formalised approaches like CPA. One advantage lies in the comparison of cases on a rational basis. Even unique projects with an extensive bargaining leeway could benefit from a concise analysis of the current situation; however, it might be more difficult to analyse conflicts within an open actor arena. Regional development processes for example, might cover so many different issues and actors, that it could be difficult to identify a particular set of actors, actor types, interests and conflict types. However, it is one open research question if there are "typical" settings, which might be valid for different policy fields and issues. The advantage of CPA lies in its moderately formalised approach that allows for the integration of non-formalised and qualitative approaches depending on the specific scope of analysis and the given constraints for data gathering.

The moderate "standardisation" of the outcomes allows for the conceptual link to different political (steering) approaches. As it was shown, the outcomes can be linked to the capacities of different participation methods in order to support the exploitation of participation-niches that are left by political programme(s). Based on these considerations, an even broader use of CPA can be suggested: CPA could be one method to inform the choice of other political governance and steering instruments, be they participatory or not. The research on Natura 2000, for example, displayed an heterogeneity of actor constellations and their prevailing power resources that could be addressed not only by participatory strategies but also by incentives and regulatory measures.

CPA combines the advantages of formalised approaches with a deeper, more qualitative analysis of different conflict types, underlying orientations, interests and power resources. The transferability to other resource management strategies seems to be promising, but has to be proved by further research.

Acknowledgements An earlier version of this paper was presented at the workshop on formalised and non-formalised methods in resource management. I would like to thank the participants and organisers, Jens Newig, Paul Burger and the anonymous reviewer for their comments. This paper has partly been drawn from research funded by the German Federal Agency for Nature Conservation (FKZ 80181 040). 


\section{Appendix}
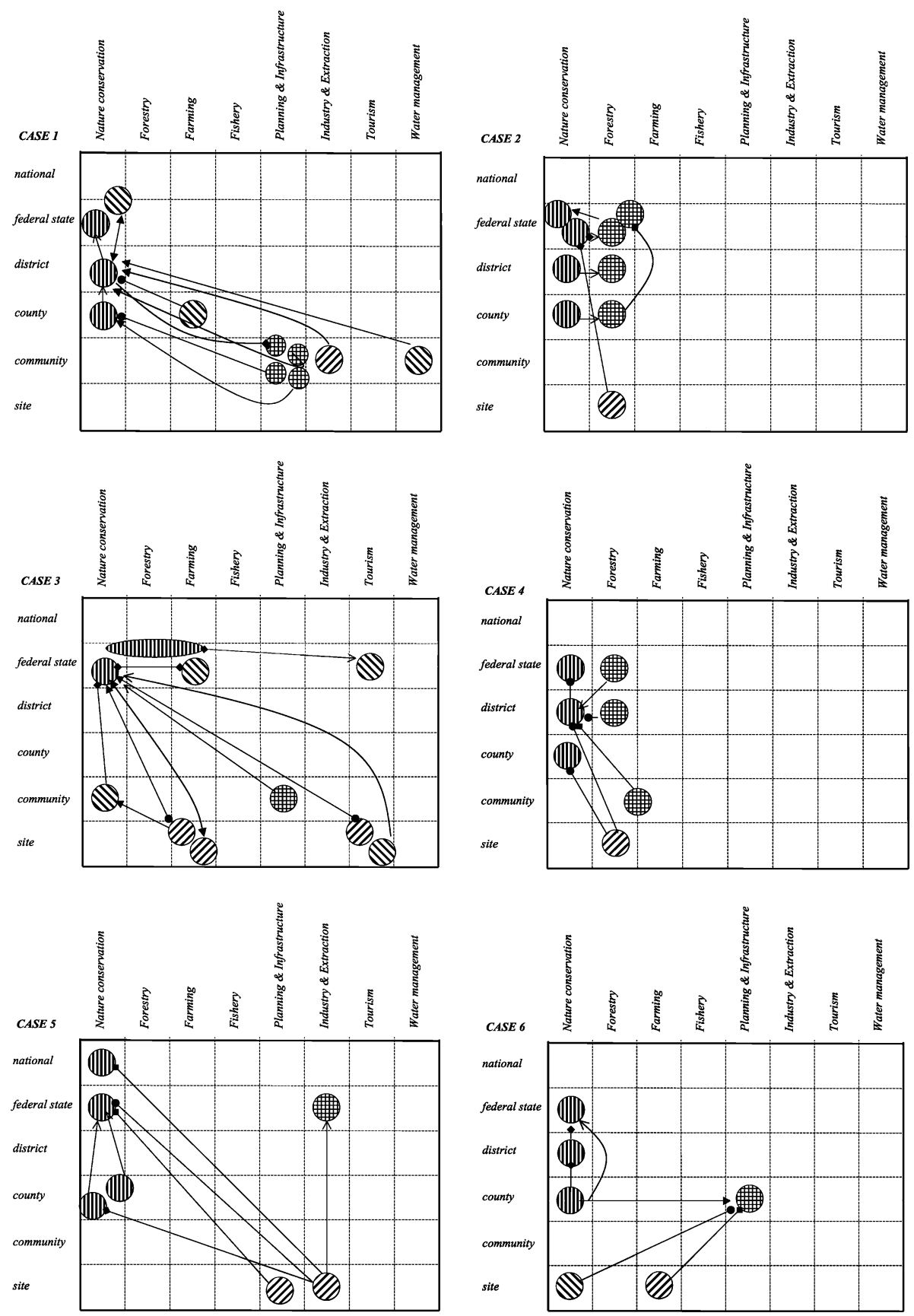



\section{References}

Beck D (2001) Sozialpsychologie kollektiver Entscheidungen. Westdeutscher Verlag, Wiesbaden Breitschuh U, Feige I (2003) Projektmanagement im Naturschutz. Westview Press, Bonn Busmann W, Klöti U, Knoepfel P (1997) Einführung in die Politikevaluation. Helbig \& Lichtenhahn, Basel CEC, Commission of the European community (2006) Seventh annual survey on the implementation and enforcement of Community environmental law 2005 SEC (2006) 1143. Brüssel, pp 70

Dahl RA (1994) A democratic dilemma: system effectiveness versus citizen participation. Political Sci Q 109(1):23-34

Esser H (1990) "Habits", "Frames" and "Rational Choice". Zeitschrift Soziologie 19(4):231-247

Geser H (1990) Organisationen als soziale Akteure. Zeitschrift Soziologie 19(6):401-417

Giesen B (1993) Die Konflikttheorie. In: Endruweit G (eds) Moderne Theorien der Soziologie: strukturellfunktionale Theorie, Konflikttheorie, Verhaltenstheorie. Westview Press, Stuttgart, pp 87-134 
Hanke R, Gray B, Putnam L (2002) Differential framing of environmental disputes by stakeholder groups. Academy of Management Conflict Mgmt. Division meetings (13171)

Healey P (1999) Deconstructing communicative planning theory: a reply to Tewdwr-Jones and Allmendinger. Environ Planning A 31:1129-1135

Hjortsø CN, Christensen SM, Tarp P (2005) Rapid stakeholder and conflict assessment for natural resource management using cognitive mapping: the case of Damdoi forest enterprise, Vietnam. Agric Hum Values 22(2):149-167

Hollstein B (2006) Qualitative Methoden und Netzwerkanalyse-ein Widerspruch? In: Hollstein B, Straus F (eds) Qualitative Netzwerkanalyse: konzepte, Methoden, Anwendungen. VS Verlag für Sozialwissenschaften, Wiesbaden, pp 11-31

Hubacek K, Prell C, Reed M, Burt T, Chapman P, Cornell S, Dougill A, Fraser E, Holden J, Irvine B, Jin N, Kirkby M, Kunin B, Quinn C, Ritsema C, Jetten V, Sendzimir J, Stagl S, Stringer L, Taylor M, Termansen M, Turner A, Worrall F (2006) Combining formalised and non-formalised methods to stimulate social learning in natural resource management. Contribution to the workshop formalised and non-formalised methods in resource management in Osnabrueck, 21-22 September 2006

Kallis G, Videira N, Antunes P, Pereira ÂG, Spash CL, Coccossis H, Corral QS, de Moral L, Hatzilacour D, Lobo G, Mexa A, Panque P, Mateos BP, Santos R (2006) Participatory methods for water resources planning. Environ Planning C 24(2):215-234

Kronenberg C (2005) Die Definition der Situation und die variable Rationalität der Akteure. Zeitschrift für Soziologie 34(5):344-363

Krott M (2001) Politikfeldanalyse Forstwirtschaft. Westview Press, Berlin

Mayntz R, Scharpf F (1995) Der Ansatz des akteurzentrierten Institutionalismus. In: Mayntz R, Scharpf F (eds) Gesellschaftliche Selbstregelung und politische Steuerung. Frankfurt/Main, Campus, pp 39-72

Newig J, Gaube V, Berkhoff K, Kaldrack K, Kastens B, Lutz J, Schlußmeier B, Adensam H, Haberl H (2006) The role of formalisation, participation and context in the success of public involvement mechanisms in resource management. Osnabrück, pp 18

Niemelä J, Young J, Alard D, Askasibar M, Henle K, Johnson R, Kurttila M, Larsson T-B, Matouch S, Nowicki P, Paiva R, Portoghesi L, Smulders R, Stevenson A, Tartes U, Watt A (2005) Identifying, managing and monitoring conflicts between forest biodiversity conservation and other human interests in Europe. Forest Policy Econ 7(6):877-890

O. D. A. (Overseas Development Administration) (1995) Guidance note on how to do stakeholder analysis of aid projects and programmes

Ostrom E (1999) Institutional rational choice-An assessment of the institutional analysis and development framework. In: Sabatier PA (eds) Theories of the policy process. Westview Press, Boulder, pp 35-71

Ostrom E (2005) Understanding institutional diversity. Princeton University Press, Princeton, p 355

Prittzwitz V (1990) Das Katastrophenparadox. Leske + Budrich, Opladen

Rauschmayer F, Wittmer H (2006) Evaluating deliberative and analytical methods for the resolution of environmental conflicts. Land Use Policy 23(1):108-122

Rowe G, Frewer LJ (2000) Public participation methods: a framework for evaluation. Sci Technol Hum Values 25(1):3-29

Sabatier PA, Jenkins-Smith H (1999) The advocacy coalition framework: an assessment. In: Sabatier PA (ed) Theories of the policy process. Westview Press, Boulder, pp 119-147

Sauer A, Luz F, Suda M, Weiland U (2006) Steigerung der Akzeptanz von FFH-Gebieten: Ansätze einer Strategie. Natur und Landschaft 81(4):193-201

Schlager E (1999) A comparison of frameworks, theories, and models of policy processes. In: Sabatier PA (ed) Theories of the policy process. Westview Press, Boulder, pp 233-260

Sneddon Ch, Harris L, Dimitrov R, Özesmi U (2002) Contested waters: conflict, scale and sustainability in aquatic socioecological systems. Soc Nat Resour 15:663-675

Soini K, Aakkula J (2007) Framing the biodiversity of agricultural landscape: the essence of local conceptions and constructions. Land Use Policy 24(2):311-322

Stark C (2000) Politischer Akteur und gesellschaftliche Machtressourcen. Zur Rationalität in Verhandlungssituationen. In: Druwe U, Kühnel S, Kunz V (eds) Kontext, Akteur und strategische Interaktion. Leske + Budrich, Opladen, pp 105-130

Stirling A (2006) Analysis, participation and power: justification and closure in participatory multi-criteria analysis. Land Use Policy 23(1):95-107

Stoll-Kleemann S (2001) Opposition to the designation of protected areas in Germany. J Environ Plan Manage 44(1):109-128

Thomas CW (2003) Bureaucratic landscapes. MIT, Cambridge

Valve H (2002) Implementation of EU rural policy: is there any room for local actors? The case of East Anglia, UK. Landscape Urban Plan 61(2-4):125-136 
van Asselt MBA, Rijkens-Klomp N (2002) A look in the mirror: reflection on participation in integrated assessment from a methodological perspective. Global Environ Change 12(3):167-184

Welp M, de la Vega-Leinert A, Stoll-Kleemann S, Jaeger CC (2006) Science-based stakeholder dialogues: theories and tools. Glob Environ Change 16(2):170-181

Zierhofer W, Burger P (2007) Transdisziplinäre Forschung-ein eigenständiger Modus der Wissensproduktion? GAIA 16(1):29-34 